\section{Therapeutic applications of melatonin}

\author{
Ifigenia Kostoglou-Athanassiou
}

Abstract: Melatonin is a methoxyindole synthesized within the pineal gland. The hormone is secreted during the night and appears to play multiple roles within the human organism. The hormone contributes to the regulation of biological rhythms, may induce sleep, has strong antioxidant action and appears to contribute to the protection of the organism from carcinogenesis and neurodegenerative disorders.

At a therapeutic level as well as in prevention, melatonin is used for the management of sleep disorders and jet lag, for the resynchronization of circadian rhythms in situations such as blindness and shift work, for its preventive action in the development of cancer, as additive therapy in cancer and as therapy for preventing the progression of Alzheimer's disease and other neurodegenerative disorders.

Keywords: antioxidant agents, circadian rhythms, jet lag, melatonin, sleep

\section{Melatonin}

Melatonin, $\mathrm{N}$-acetyl-5-methoxytryptamine, is a methoxyindole which is synthesized within the pineal cells [Zawilska et al. 2009]. Steadily accumulating data show that melatonin has many beneficial effects in humans.

The pineal is involved in many functions of the organism via secretion of the hormone melatonin, which is characterized by functional pleiotropy [Reiter, 1995]. Melatonin is synthesized from tryptophan within the pineal cells, its secretion starting in the absence of light, being high during the night, the reverse happening during the day. Melatonin receptors have been detected on the cell surface [Reiter et al. 2010; Dubocovich et al. 2010]. In humans, melatonin receptors have been detected in the retina, brain, suprachiasmatic nucleus, pars tuberalis, ovaries, cerebral and peripheral arteries, kidney, pancreas, adipocytes and immune cells [Dubocovich and Markowska, 2005; Dubocovich et al. 2010].

Melatonin is thought to be involved in the adaptation of the organism to the light-dark cycle of the environment. There is evidence that it is involved in the regulation of biological rhythms. The hormone affects the function of both the anterior and posterior lobe of the pituitary [Kostoglou-Athanassiou et al. 1998b, 1998c]. Nocturnal melatonin secretion is increased in premenopausal women on contraceptive pills [Kostoglou-Athanassiou et al. 1998a], as well as in postmenopausal women. Administration of the hormone in humans may contribute to the management of jet lag [Herxheimer and Petrie, 2002], the disorder observed after transatlantic flights. The hormone is involved in the regulation of the immune system [Giannoulia-Karantana et al. 2006] and is a potent antioxidant agent [Tan et al. 2007]. Melatonin may contribute to the conservation of DNA integrity and may thus be involved in cancer prevention. Other research data show that the hormone is a natural oncostatic agent, being involved in protection from the development of malignant neoplasms. Melatonin may soon find clinical applications as it has been successfully used in cancer therapy and in the management of the adverse effects of anticancer therapy.

In this review a referral will be made to the relationship of melatonin with sleep disorders, the use of melatonin in the entrainment of biological rhythms and the management of jet lag, the antioxidant action of melatonin, the relationship of melatonin with cancer, the relationship of melatonin with the immune system, the relationship of melatonin with rheumatoid arthritis and the relationship of melatonin with Alzheimer's disease and other neurodegenerative disorders.
Ther Adv Endocrinol

Metab

(2013) 4(1) 13-24

DOI: $10.1177 /$

2042018813476084

(c) The Author(s), 2013. Reprints and permissions: http://www.sagepub.co.uk/ journalsPermissions.nav

Correspondence to: Ifigenia KostoglouAthanassiou, MSc, MD, PhD

Department of

Endocrinology, Red Cross Hospital, 7 Korinthias

Street, Athens, GR115 26 , Greece

ikostoglouathanassioula yahoo.gr 


\section{Melatonin and sleep disorders}

Melatonin may be used for the management of sleep disorders, such as insomnia and the disorder arising from night or shift work [Cardinali et al. 2011; Fares, 2011; Hardeland et al. 2008; Khan et al. 2011; Malow et al. 2012; Morin et al. 2007; Ochoa-Sanchez et al. 2011; Skene and Arendt, 2006; Srinivasan et al. 2008, 2011a]. When endogenous melatonin secretion is decreased, such as in people of advanced age or in those who use $\beta$ blockers [Fares, 2011], or the natural circadian rhythm of melatonin is affected, such as in shift workers or people who are blind [Khan et al. 2011], exogenous melatonin administration may improve the quality and duration of sleep. In patients with insomnia, melatonin seems to induce the onset of sleep, however its hypnotic action is mild. The advantages of melatonin in relation to other sleep-inducing agents are the absence of hangover the morning after, the absence of withdrawal symptoms and the absence of addiction [Hardeland et al. 2008; Srinivasan et al. 2008]. However, melatonin has a short half life in the circulation and mild hypnotic action. Therefore, melatonin analogs have been introduced, such as ramelteon (CAS 196597-26-9) and agomelatine (CAS 138112-76-2) [Hardeland et al. 2008]. Ramelteon has a high affinity for melatonin receptors $\mathrm{MT}_{1}$ and $\mathrm{MT}_{2}$ in the suprachiasmatic nucleus and a longer half life than melatonin, having been used successfully for the management of insomnia. Agomelatine has a high affinity for melatonin receptors $\mathrm{MT}_{1}$ and $\mathrm{MT}_{2}$ in the suprachiasmatic nucleus, also acting as a serotonin antagonist, and it has hypnotic and antidepressive action.

\section{Melatonin and circadian rhythms}

In people who are blind or those who work shifts the administration of melatonin may help in the synchronization of biological rhythms to the environment [Bjorvatn and Pallesen, 2009; Cardinali et al. 2006; Claustrat et al. 2001; Coogan and Thorne, 2011; Dallaspezia and Benedetti, 2011; Hickie and Rogers, 2011; Lewy et al. 1996; Morgenthaler et al. 2007; PandiPerumal et al. 2007, 2008; Pevet and Challet, 2011; Sanchez-Barcelo et al. 2011; Skene et al. 1999; Thorpy, 2011; Warman et al. 2011; Zisapel, 2001; Zee and Manthena, 2007]. Melatonin may prove to be useful in the management of affective disorders, such as seasonal affective disorder [Coogan and Thorne, 2011; Dallaspezia and Benedetti, 2011; Hickie and Rogers, 2011]. Melatonin acts on $\mathrm{MT}_{1}$ and $\mathrm{MT}_{2}$ receptors in the suprachiasmatic nucleus of the hypothalamus, the locus of the main circadian regulator. Melatonin resynchronizes the disordered circadian rhythms and induces sleep in people with delayed sleep phase syndrome and in shift workers. Ramelteon and agomelatine, melatonin receptor agonists with a longer half life and higher affinity for melatonin receptors, have great potential for the management of biological rhythm disorders.

\section{Melatonin and jet lag}

Melatonin may be used successfully for the prevention and treatment of jet lag [Herxheimer and Petrie, 2002; Jackson, 2010; Michalik and Bobinski, 2009; Sack, 2010; Paul et al. 2010; Rios et al. 2010; Sánchez-Barceló et al. 2010; Srinivasan et al. 2008; Zee et al. 2010; Zee and Goldstein, 2010]. Jet lag is often observed in transatlantic travelers crossing several time zones. It arises as a result of lack of synchronization of the endogenous rhythm of the organism with the light-dark cycle of the environment in the destination area. Melatonin plays a central role in the regulation of biological rhythms. The effect of oral administration of melatonin on jet lag after transatlantic flights crossing several time zones was evaluated [Herxheimer and Petrie, 2002]. Controlled studies in the Cochrane database and in the databases Medline, Embase, Psychlit and Science Citation Index were reviewed. It was found that melatonin, when taken before sleep time in the destination area, that is between 10 p.m. and 12 p.m., reduces jet lag arising after flights crossing five or more time zones. Daily melatonin doses from 0.5 to $5 \mathrm{mg}$ are equally effective, people sleeping quicker and better after taking $5 \mathrm{mg}$. Doses larger than $5 \mathrm{mg}$ do not seem to be more effective. The benefit seems to be greater the more time zones are crossed and smaller for western flights. The timing of melatonin administration seems to be important because if melatonin is taken early during the day it induces sleepiness, thus delaying adaptation to the local time. Other side effects are rare. It appears that patients with epilepsy and those on warfarin may have adverse effects from melatonin administration. Melatonin use is indicated in adult travelers crossing five or more time zones, especially those traveling eastwards who have previously been affected by jet lag. Travelers crossing two to four time zones may also use melatonin if they need it. In travelers crossing seven to eight time zones the administration of melatonin on arrival at the destination area is enough; however, 
when more time zones are crossed melatonin should be administered for 2-3 days before the flight, its hypnotic and sedative action being appropriately managed [Srinivasan et al. 2008]. Recently, the field of circadian typology has been developing, that is, the field describing individual differences in the behaviour of the individual according to the time of day, which affects biological and psychological functioning, not only in healthy people but also in those with disease. Melatonin is a biological marker involved in defining the circadian typology of each individual [Adan et al. 2012]. The circadian typology of the individual also affects the type of adjustment to shift work and jet lag and the need for melatonin treatment. It appears that chronobiological aspects of human behaviour should be taken into account when jet lag should be managed or the need for adjustment to shift work arises. Melatonin products need systematic quality control. In conclusion, melatonin is effective in the prevention and treatment of jet lag.

\section{Melatonin and antioxidant action}

Melatonin is a very potent free radical recipient and a general antioxidant. As an antioxidant melatonin binds potently the toxic hydroxyl and hyperoxide radicals. The antioxidant properties of melatonin have been proved in homogenized tissues and in living organisms [Acuña Castroviejo et al. 2011; Aversa et al. 2012; Galano et al. 2011; Gitto et al. 2012; Reiter et al. 2011a, 2011b; Tan et al. 2007]. The antioxidant action of melatonin is exerted both directly and via its metabolites [Tan et al. 2007]. The property of melatonin to act as an antioxidant by itself and through its metabolites makes it extremely effective, even at a low concentration, in the protection of living organisms from oxidative stress. In agreement with melatonin's protective function, significant amounts of melatonin have been detected in tissues and organs exposed to hostile environmental attacks, such as the skin and the bowel, and in organs with high oxygen consumption, such as the brain, melatonin production being increased by agents inducing low-intensity stress, such as exercise in humans. Intense oxidative stress results in an acute decrease in circulating melatonin levels as a result of its consumption, as it is known to be a suicidal antioxidant, being consumed during its antioxidant action [Galano et al. 2011]. During the recent disaster in Japan, melatonin was used to prevent the damage induced by ionizing radiation [Reiter $e t$ al. 2011b].

\section{Melatonin and cancer}

Melatonin seems to contribute to cancer prevention and may also be used as additive therapy in cancer.

\section{Melatonin and protection from carcinogenesis}

Melatonin seems to have an oncostatic action and appears to contribute to anticancer protection [Bukowska, 2011; Hrushesky et al. 2009; McCarty, 2012; McCune et al. 2011; Mao et al. 2010; Mediavilla et al. 2010; Ravindra et al. 2006; Santoro et al. 2012; Schernhammer et al. 2011; Vijayalaxmi et al. 2002].

Many studies have shown that melatonin inhibits the growth of breast cancer cells, cervical cancer cells and ovarian cancer cells. Melatonin is a new member of a group of regulatory factors controlling cell multiplication and death and is a chronobiotic hormonal regulator of the growth of neoplasmatic cells [Blask et al. 2002]. In physiologic concentrations melatonin is cytostatic and inhibits cancer cell multiplication via action in the cell cycle. In pharmacologic concentrations melatonin has a cytotoxic effect on cancer cells. In physiologic and pharmacologic concentrations it acts as a differentiating factor in some cancer cells, reducing their infiltrative and metastatic potential via alteration of binding molecules and conservation of intracellular communication. In other types of cancer cells melatonin either alone or in combination with other factors induces cancer cell apoptosis. Biochemical and molecular mechanisms of the oncostatic action of melatonin include regulation of expression and activation of estrogen receptors via calmodulin, modulation of the cytoskeleton architecture and function, and modulation of intracellular oxidative status via the cell surface melatonin receptors.

Data show that melatonin inhibits carcinogenesis. Exposure to magnetic fields of $50-60 \mathrm{~Hz}$ increases breast cancer risk, possibly via inhibition of melatonin secretion [Liburdy et al. 1993]. In rats, having been exposed to the carcinogen 7,12-dimethylbenz $[\alpha]$ anthracene (DMBA), blindness and food restriction prevent the appearance of breast adenocarcinoma, this result being dependent on the presence of the pineal [Bartsch et al. 1995]. Food restriction may be related to an increase in melatonin secretion, while blindness leads to the appearance of free rhythms and a strong melatonin signal. This increase seems to be 
related to an improvement in the natural defense mechanisms of the organism. In rats developing breast cancer after exposure to the carcinogen DMBA, pinealectomy increased the frequency of cancer development while afternoon melatonin administration decreased it.

Indomethacin and melatonin administration inhibits breast cancer development after the administration of DMBA [Mcikova-Kalicka et al. 2001]. Melatonin administration in laboratory animals, in which skin carcinogenesis had been induced by benzo-a-pyrene, reduces the number of papillomas in the initiation and progression of carcinogenesis [Kumar and Das, 2000].

\section{Melatonin and cancer management}

Melatonin may be used as an adjuvant in cancer therapy [Dopfel et al. 2007; Han et al. 2011; Hansen et al. 2012; Jung and Ahmad, 2006; Knower et al. 2012; Lissoni et al. 1995b, 2001; Lissoni, 2002; Seely et al. 2011; Shirazi et al. 2007; Srinivasan et al. 2011b; Zha et al. 2012].

The experimental studies led to clinical studies, in which melatonin was administered along with tamoxifen in women with metastatic breast cancer, which had progressed despite the administration of tamoxifen. It was found that the simultaneous administration of melatonin and tamoxifen may contribute to the objective regression of cancer in women with metastatic breast cancer not responding to tamoxifen alone [Lissoni et al. 1995b].

Studies suggested that the biological response of the host organism to the neoplasm to interleukin 2 may be modulated by the administration of immune-modulating factors, such as melatonin. The parallel administration of melatonin with interleukin 2 in patients with distant metastases in non-small cell lung carcinoma, liver carcinoma, bowel carcinoma, stomach carcinoma, pancreatic carcinoma and breast cancer contributes to cancer regression and disease stabilization [Lissoni et al. 1993].

Melatonin, when used in combination with interleukin 2 in cancer immunotherapy contributes to the prevention of thrombocytopenia, a frequent hematologic complication of interleukin 2 therapy [Lissoni et al. 1995a]. Recent studies have shown that the hemopoietic system is under neuroendocrine control [Lissoni et al. 2001], thrombopoeisis having been shown to be stimulated by melatonin and melatonin shown to be effective in thrombocytopenia therapy.

The number of lymphocytes is one of the most important parameters of the immune system which contribute to the prognosis of patients with progressive cancer. Interleukin 2 and interleukin 12 are the most important cytokines with antineoplastic action in the human organism. The action of these cytokines is modulated by the neuroendocrine system, especially the pineal via the diurnal variation of melatonin secretion [Srinivasan et al. 2011b].

The effect of melatonin was investigated in a group of 1440 patients with progressive solid cancer who received supportive therapy with or without melatonin [Lissoni et al. 1995b]. The frequency of cachexia, thrombocytopenia and lymphopenia was significantly lower in patients receiving melatonin than in those receiving only supportive therapy. The percentage of patients with disease stabilization and the annual survival were higher in patients receiving melatonin than in those receiving only supportive therapy. The objective response of patients to therapy was significantly greater in patients receiving melatonin and chemotherapy than those receiving only chemotherapy. Melatonin decreased the frequency of cachexia, thrombocytopenia, stomatitis, cardiotoxicity and neurotoxicity due to chemotherapy.

Radiotherapy is a frequent and effective form of cancer therapy. The sensitivity of normal tissues, which are near the neoplasm and are inevitably exposed to radiation, decreases the therapeutic benefit. As ionizing radiation has destructive effects, radiobiologists are interested in the recognition of novel, nontoxic, effective and easy to use methods for the prevention of the damage induced on healthy tissues by radiation. In many studies, melatonin has been proved to decrease the oxidative damage induced by ionizing radiation. Data show that melatonin may be used as a radioprotective agent in patients with cancer either alone for cancer inhibition or in combination with traditional radiotherapy with the aim of a better effectiveness/toxicity ratio [Shirazi et al. 2007].

A variety of cytokines and growth factors exert a fine-tuning action in a series of productive and differentiating functions involved in hemopoiesis. Studies have shown that neuroendocrine and 
neural agents may be involved in the control of hemopoiesis. Melatonin, in particular, may salvage hemopoiesis from the toxic effect of antineoplastic drugs via opioid cytokines of T-helper cells [Maestroni, 1999a].

These studies show that melatonin may be used successfully in clinical oncology as supportive therapy in patients with progressive cancer and for the prevention of toxicity induced by chemotherapy and radiotherapy [Jung and Ahmad, 2006; Dopfel et al. 2007]. In conclusion, melatonin may contribute to the protection of organisms from carcinogenesis, being involved in cancer prevention, and may be used as an adjuvant in cancer therapy.

\section{Melatonin and the immune system}

A series of experimental studies show that there is a close connection between the pineal and the immune system [Carrillo-Vico et al. 2005]. In several species pinealectomy or any experimental process which inhibits the synthesis and secretion of melatonin induces a state of immunosuppression, this state being reversed by the administration of melatonin. Melatonin has an immunoenhancing effect [Carrillo-Vico et al. 2006]. Melatonin activates $T$ lymphocytes, monocytes, natural killer cells and even granulocytes, activates cell-dependent cytotoxicity and induces antibody-dependent responses in vivo. In experimental models in animals, as well as in human studies and in experiments in vitro, melatonin induces the production of inflammatory cytokines and nitric oxide. The effect of glucocorticoids in vitro on the immune function seems to be modulated by melatonin in physiologic and pharmacologic concentrations. It has been proved that melatonin is involved in lymphocyte number control [Lissoni et al. 2008]. It has been found that $\mathrm{T}$ lymphocytes express cell membrane melatonin receptors. The activation of these receptors by melatonin induces cytokine release, such as interferon $\gamma$ and interleukin 2 as well as opioid cytokines. Melatonin has been reported to increase the production of interleukin 1 , interleukin 6 and interleukin 12 in human monocytes [Lissoni, 1999]. These cell mediators may be involved in the counterbalance of immunosuppression induced by stress as well as in other forms of secondary immunosuppression. Melatonin may protect mice from viral encephalitis, bacterial diseases and septic shock. Melatonin may have immunotherapeutic potential in viral and bacterial infections [Maestroni, 1999b]. Melatonin may be used for the stimulation of immune response during viral and bacterial infections and may reinforce the immune reaction during viral and bacterial infections, acting as a protective agent for the organism. However, melatonin through its proinflammatory action may have a deteriorating effect in autoimmune diseases. In multiple sclerosis the role of melatonin has not been elucidated. In mice, which are susceptible to the development of systemic lupus erythematosus, the effect of melatonin depends on the sex of the animal [Jimenez-Caliani et al. 2006].

\section{Melatonin and rheumatoid arthritis}

It appears that rheumatoid arthritis is more frequent and more severe in northern countries where the population is exposed to higher melatonin concentrations as a result of longer nights and longer and heavier winters as opposed to the southern Mediterranean countries [Cutolo et al. 2005]. Morning stiffness in rheumatoid arthritis may be related to the proinflammatory action of melatonin during the night [Cutolo et al. 2003, 2008]. These observations are in accordance with the immune-enhancing action of melatonin.

Nocturnal melatonin levels have been found to be higher in patients with rheumatoid arthritis than in healthy controls [Sulli et al. 2002]. Melatonin has been detected in high concentrations in the articular fluid in patients with rheumatoid arthritis and melatonin receptors have been detected in the macrophages of the synovial membrane. It is interesting that the production of interferon $\gamma$, interleukin 2, interleukin 6, interleukin 12 and tumor necrosis factor $\alpha$ has a nocturnal and an early morning peak soon after the melatonin peak and during the nadir of cortisol secretion [Petrovsky et al. 1998]. These observations are in accordance with the hypothesis that melatonin increases cytokine production and immune system activity.

In a double-blind controlled study investigating the effect of melatonin administration on patients with rheumatoid arthritis, melatonin was found to be a strong antioxidant in vivo, the red cell sedimentation rate being increased after melatonin administration and rheumatoid arthritis not improving or even deteriorating in some patients [Forrest et al. 2007]. These observations are in accordance with the antioxidant action of melatonin, suggesting a proinflammatory effect [Korkmaz, 2008; Korkmaz and Reiter, 2008]. 


\section{Melatonin and neurodegenerative disorders}

Studies in mice show that melatonin administration may inhibit the appearance of neural cell abnormalities and the attendant memory disturbance which are observed in Alzheimer's disease. Continuous light exposure in rats induces the appearance of changes related to those observed in Alzheimer's disease while melatonin administration protects against their appearance [Ling et al. 2009]. In humans with Alzheimer's disease, disorders in melatonin secretion and biological rhythm disorders are observed, alterations which may be related to degeneration of the retina, suprachiasmatic nucleus, pineal axis and disturbance of the regulation of melatonin secretion from the sympathetic system. Melatonin may be used therapeutically for the resynchronization of the biological rhythms and the prevention of histological changes in Alzheimer's disease [Olcese et al. 2009]. Melatonin has a potential therapeutic value as a neuroprotective agent in Parkinson's disease, amyotrophic lateral sclerosis, Huntington's disease and brain trauma [Pandi-Perumal et al. 2012; Rothman and Mattson, 2012; Srinivasan et al. 2011a]. Clinical trials using melatonin are warranted before its relative merits as a neuroprotective agent are definitively established.

\section{Mode of action of melatonin}

Melatonin exerts its effects through activation of at least two high-affinity G-protein-coupled receptors, $\mathrm{MT}_{1}$ and $\mathrm{MT}_{2}$ [Dubocovich and Markowska, 2005; Dubocovich et al. 2010]. These are unique receptors as they show distinct molecular structures, pharmacological characteristics and chromosomal localization [Masana and Dubocovich, 2001]. The $M T_{1}$ and $M T_{2}$ receptors are 350 and 362 amino acids long respectively, with calculated molecular weights of $39-40 \mathrm{kDa} . \mathrm{MT}_{1}$ and $\mathrm{MT}_{2}$ melatonin receptors signal by coupling to heterotrimeric Gi proteins formed by $\alpha, \beta$ and $\gamma$ subunits [Masana and Dubocovich, 2001; Dubocovich et al. 2003]. Activation of these receptors promotes dissociation of $\mathrm{G}$ proteins into $\alpha$ and $\beta, \gamma$ dimers, which interact with various effector molecules involved in the transmission of cell signaling. Effector systems involved in $\mathrm{MT}_{1}$ and $\mathrm{MT}_{2}$ melatonin receptor signaling through G-protein coupling include adenylyl cyclase, phospholipase C, phospholipase A2, potassium channels and potentially guanylyl cyclase and calcium channels.

Tissues endowed with fully characterized functional $\mathrm{MT}_{1}$ and $\mathrm{MT}_{2}$ melatonin receptors include the retina, brain, suprachiasmatic nucleus, pars tuberalis, ovaries, cerebral and peripheral arteries, kidney, pancreas, adipocytes and immune cells [Dubocovich and Markowska, 2005; Dubocovich et al. 2010] (Figure 1).

The retina produces melatonin locally and expresses both the $\mathrm{MT}_{1}$ and $\mathrm{MT}_{2}$ melatonin receptors [Scher et al. 2002]. $\mathrm{MT}_{1}$ melatonin receptors are expressed in rod photoreceptor cells. Both the $\mathrm{MT}_{1}$ and $\mathrm{MT}_{2}$ melatonin receptors are found in the suprachiasmatic nuclei, being localized primarily to neuronal elements

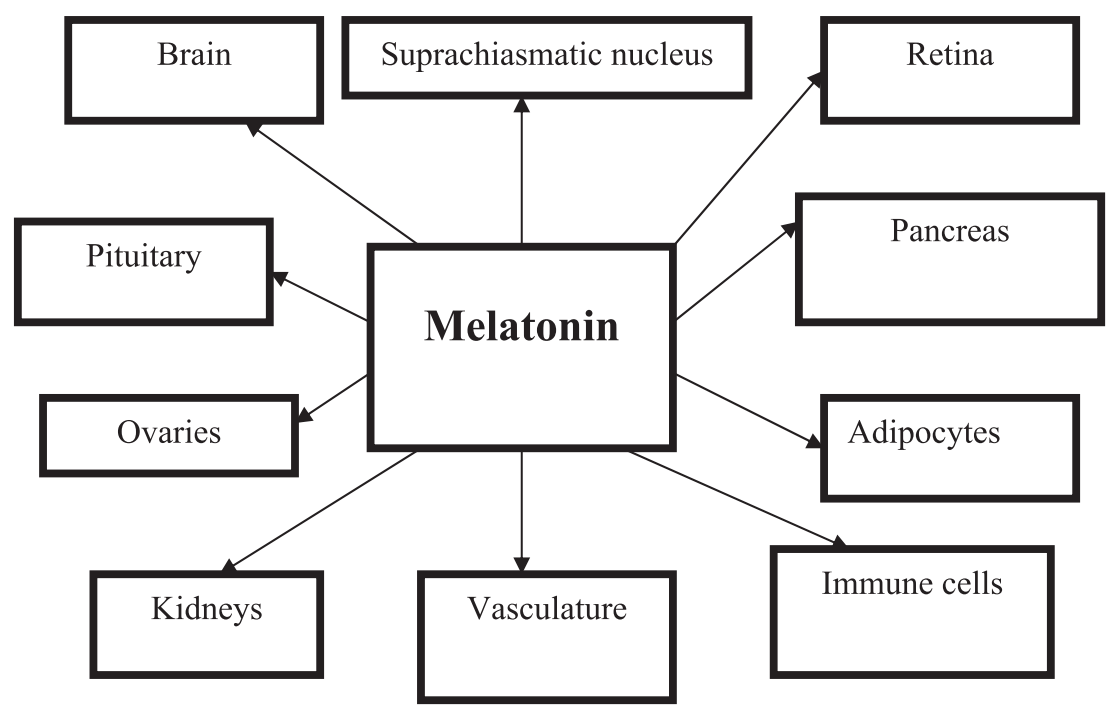

Figure 1. Target tissues of melatonin in humans. 
[Rivera-Bermudez et al. 2004]. The suprachiasmatic nucleus is the master clock controlling behavioral, metabolic and physiological rhythms, including the synthesis and release of melatonin from the pineal gland. Endogenous pineal melatonin feeds back onto the master clock and regulates neuronal activity and circadian rhythms through activation of $\mathrm{MT}_{1}$ and $\mathrm{MT}_{2}$ melatonin receptors. In the suprachiasmatic nucleus melatonin inhibits neuronal firing via $\mathrm{MT}_{1}$, but it phase shifts neuronal firing rhythms through activation of $\mathrm{MT}_{2}$ melatonin receptors [Dubocovich et al. 2005]. Melatonin receptors have been localized in the human brain, as $\mathrm{MT}_{1}$ and $\mathrm{MT}_{2}$ melatonin receptor mRNA has been amplified from human brain cerebellum, occipital cortex, parietal cortex, temporal cortex, thalamus, frontal cortex hippocampus and suprachiasmatic nucleus [Mazzucchelli et al. 1996].

Melatonin receptors have been found in the pars tuberalis of the anterior pituitary [Dubocovich et al. 2010], as well as in the ovaries [Niles et al. 1999]. In the pars tuberalis of the anterior pituitary gland, the nocturnal secretion of melatonin suppresses the expression of the clock gene Per 1 by inhibiting the cAMP-dependent signaling pathway through activation of the $\mathrm{MT}_{1}$ receptor [von Gall et al. 2002]. At dawn when circulating melatonin levels decrease, the pars tuberalis is released from transcriptional repression, facilitating the induction of Per 1 gene expression. Furthermore, during the biological night, endogenous melatonin through activation of the $\mathrm{MT}_{1}$ melatonin receptor inhibits prolactin release in the pars tuberalis [Dubocovich et al. 2010]. This appears to be a general mechanism by which the hormone melatonin regulates gene expression to link the central circadian pacemaker and peripheral tissues, resulting in modulation of circadian and seasonal rhythms.

Pancreatic islets [Peschke et al. 2007] and adipocytes [Brydon et al. 2001] express melatonin receptors. $\mathrm{MT}_{1}$ and $\mathrm{MT}_{2}$ melatonin receptors have been detected in peripheral and cerebral arteries [Ekmekcioglu, 2006]. $\mathrm{MT}_{1}$ melatonin receptor localization in the arterial wall and hippocampal microvasculature of normal subjects and patients with Alzheimer's disease suggest involvement of melatonin in the regulation of cerebral blood flow [Savaskan et al. 2001]. In the vascular system melatonin evokes opposite responses, as it potentiates vasoconstriction through $\mathrm{MT}_{1}$ and induces vasodilatation via $\mathrm{MT}_{2}$ receptors [Dubocovich et al. 2010]. Melatonin receptors have also been detected in the human kidney [Drew et al. 1998]. Melatonin membrane receptors are expressed in lymphocytes and are involved at least in part in regulating immune responses [Pozo et al. 2004].

Membrane melatonin receptors appear to be involved in melatonin's oncostatic effect. Prostate tumor and breast cancer cells express melatonin receptors [Dillon et al. 2002; Gilad et al. 1999; Rögerlsperger et al. 2011]. Colon cancer cells also express melatonin receptors [Nemeth et al. 2011], melatonin's oncostatic action being mediated primarily through activation of $\mathrm{MT}_{1}$ melatonin receptors.

Melatonin-mediated effects are time dependent, with the efficacy of melatonin being probably dependent on the diurnal sensitivity of $\mathrm{MT}_{1}$ and $\mathrm{MT}_{2}$ melatonin receptor expression. The in-depth study of melatonin receptor function will facilitate discovery and development of novel agents for the treatment of sleep, circadian, metabolic and endocrine disorders, as well as tumor cell growth.

\section{Conclusion}

Melatonin is a hormone with multiple actions. It is involved in the regulation of biological rhythms, in sleep regulation, it has potent antioxidant action and protects the organism from carcinogenesis and neurodegenerative disorders. The hormone possesses immune-enhancing activity. Therapeutically, it may be used for the management of insomnia, jet lag, the resynchronization of circadian rhythms, as an adjuvant in cancer therapy and in the inhibition of disease progression in Alzheimer's disease and other neurodegenerative disorders.

\section{Funding}

This research received no specific grant from any funding agency in the public, commercial, or not-for-profit sectors.

\section{Conflict of interest statement}

The authors declare no conflicts of interest in preparing this article.

\section{References}

Acuña Castroviejo, D., López, L., Escames, G., López, A., García, J. and Reiter, R. (2011) 
Melatonin-mitochondria interplay in health and disease. Curr Top Med Chem 11: 221-240.

Adan, A., Archer, S., Hidalgo, M., Di Milia, L., Natale, V. and Randler, C. (2012) Circadian typology: a comprehensive review. Chronobiol Int 29:1153-1175.

Aversa, S., Pellegrino, S., Barberi, I., Reiter, R. and Gitto, E. (2012) Potential utility of melatonin as an antioxidant during pregnancy and in the perinatal period. F Matern Fetal Neonatal Med 25: 207-221.

Bartsch, C., Bartsch, H., Buchberger, A., Rokos, H., Mecke, D. and Lippert, T. (1995) Serial transplants of DMBA-induced mammary tumors in Fischer rats as model system for human breast cancer. IV. Parallel changes of biopterin and melatonin indicate interactions between the pineal gland and cellular immunity in malignancy. Oncology 52: 278-283.

Bjorvatn, B. and Pallesen, S. (2009) A practical approach to circadian rhythm sleep disorders. Sleep Med Rev 13: 47-60.

Blask, D., Sauer, L. and Dauchy, R. (2002) Melatonin as a chronobiotic/anticancer agent: cellular, biochemical, and molecular mechanisms of action and their implications for circadian-based cancer therapy. Curr Top Med Chem 2: 113-132.

Brydon, L., Petit, L., Delagrange, P., Strosberg, A. and Jockers, R. (2001) Functional expression of MT2 (Mel1b) melatonin receptors in human PAZ6 adipocytes. Endocrinology 142: 4264-4271.

Bukowska, A. (2011) Anticarcinogenic role of melatonin - potential mechanisms. $\operatorname{Med} \operatorname{Pr} 62$ : 425-434.

Cardinali, D., Furio, A., Reyes, M. and Brusco, L. (2006) The use of chronobiotics in the resynchronization of the sleep-wake cycle. Cancer Causes Control 17: 601-609.

Cardinali, D., Pagano, E., Scacchi Bernasconi, P., Reynoso, R. and Scacchi, P. (2011) Disrupted chronobiology of sleep and cytoprotection in obesity: possible therapeutic value of melatonin. Neuro Endocrinol Lett 32: 588-606.

Carrillo-Vico, A., Guerrero, J., Lardone, P. and Reiter, R. (2005) A review of the multiple actions of melatonin on the immune system. Endocrine 27: 189-200.

Carrillo-Vico, A., Reiter, R., Lardone, P., Herrera, J., Fernández-Montesinos, R., Guerrero, J. et al. (2006) The modulatory role of melatonin on immune responsiveness. Curr Opin Investig Drugs 7: 423-431.

Claustrat, B., Brun, J. and Borson-Chazot, F. (2001) Melatonin and circadian rhythm. Rev Neurol (Paris) 157: S121-S125.
Coogan, A. and Thorne, J. (2011) Chronotherapeutics and psychiatry: setting the clock to relieve the symptoms. World F Biol Psychiatry 12(Suppl. 1): 40-43.

Cutolo, M., Maestroni, G., Otsa, K., Aakre, O., Villaggio, B., Capellino, S. et al. (2005) Circadian melatonin and cortisol levels in rheumatoid arthritis patients in winter time: a north and south Europe comparison. Ann Rheum Dis 64: 212-216.

Cutolo, M., Seriolo, B., Craviotto, C., Pizzorni, C. and Sulli, A. (2003) Circadian rhythms in RA. Ann Rheum Dis 62: 593-596.

Cutolo, M., Straub, R. and Buttgereit, F. (2008) Circadian rhythms of nocturnal hormones in rheumatoid arthritis: translation from bench to bedside. Ann Rheum Dis 67: 905-908.

Dallaspezia, S. and Benedetti, F. (2011)

Chronobiological therapy for mood disorders. Expert Rev Neurother 11: 961-970.

Dillon, D., Easley, S., Asch, B., Cheney, R., Brydon, L., Jockers, R. et al. (2002) Differential expression of high-affinity melatonin receptors (MT1) in normal and malignant human breast tissue. Am $\mathcal{F}$ Clin Pathol 118: 451-458.

Dopfel, R., Schulmeister, K. and Schernhammer, E. (2007) Nutritional and lifestyle correlates of the cancer-protective hormone melatonin. Cancer Detect Prev 31: 140-148.

Drew, J., Williams, L., Hannah, L., Barrett, P. and Abramovich, D. (1998) Melatonin receptors in the human fetal kidney: 2 [125I] iodomelatonin binding sites correlated with expression of Mel1 a and Mel1b receptor genes. F Endocrinol 156: 261-267.

Dubocovich, M., Delagrange, P., Krause, D., Sugden, D., Cardinali, D. and Olcese, J. (2010) International Union of Basic and Clinical Pharmacology. LXXV. Nomenclature, classification, and pharmacology of $\mathrm{G}$ protein-coupled melatonin receptors. Pharmacol Rev 62: 343-380.

Dubocovich, M., Hudson, R., Sumaya, I., Masana, M. and Manna, E. (2005) Effect of MT1 melatonin receptor deletion on melatonin-mediated phase shift of circadian rhythms in the C57BL/6 mouse. $f$ Pineal Res 39: 113-120.

Dubocovich, M. and Markowska, M. (2005) Functional MT1 and MT2 melatonin receptors in mammals. Endocrine 27: 101-110.

Dubocovich, M., Rivera-Bermudez, M., Gerdin, M. and Masana, M. (2003) Molecular pharmacology, regulation and function of mammalian melatonin receptors. Front Biosci 8: d1093-d1108.

Ekmekcioglu, C. (2006) Melatonin receptors in humans: biological role and clinical relevance. Biomed Pharmacother 60: 97-108. 
Fares, A. (2011) Night-time exogenous melatonin administration may be a beneficial treatment for sleeping disorders in beta blocker patients. f Cardiovasc Dis Res 2: 153-155.

Forrest, C., Mackay, G., Stoy, N., Stone, T. and Darlington, L. (2007) Inflammatory status and kynurenine metabolism in rheumatoid arthritis treated with melatonin. Br f Clin Pharmacol 64: 517-526.

Galano, A., Tan, D. and Reiter, R. (2011)

Melatonin as a natural ally against oxidative stress: a physicochemical examination. F Pineal Res 51: $1-16$.

Giannoulia-Karantana, A., Vlachou, A., Polychronopoulou, S., Papassotiriou, I. and Chrousos, G. (2006) Melatonin and immunomodulation: connections and potential clinical applications. Neuroimmunomodulation 13: 133-144.

Gilad, E., Laufer, M., Matzkin, H. and Zisapel, N. (1999) Melatonin receptors in PC3 human prostate tumor cells. F Pineal Res 26: 211-220.

Gitto, E., Aversa, S., Salpietro, C., Barberi, I., Arrigo, T., Trimarchi, G. et al. (2012) Pain in neonatal intensive care: role of melatonin as an analgesic antioxidant. F Pineal Res 52: 291-295.

Han, Y., Demorrow, S., Invernizzi, P., Jing, Q., Glaser, S., Renzi, A. et al. (2011) Melatonin exerts by an autocrine loop antiproliferative effects in cholangiocarcinoma: its synthesis is reduced favoring cholangiocarcinoma growth. Am $\mathcal{F}$ Physiol Gastrointest Liver Physiol 301: G623-G633.

Hansen, M., Madsen, M., Hageman, I., Rasmussen, L., Bokmand, S., Rosenberg, J. et al. (2012) The effect of MELatOnin on Depression, anxietY, cognitive function and sleep disturbances in patients with breast cancer. The MELODY trial: protocol for a randomised, placebo-controlled, double-blinded trial. BMF Open 2: e000647.

Hardeland, R., Poeggeler, B., Srinivasan, V., Trakht, I., Pandi-Perumal, S. and Cardinali, D. (2008) Melatonergic drugs in clinical practice. Arzneimittelforschung 58: 1-10.

Herxheimer, A. and Petrie, K. (2002) Melatonin for the prevention and treatment of jet lag. Cochrane Database Syst Rev (2): CD001520.

Hickie, I. and Rogers, N. (2011) Novel melatoninbased therapies: potential advances in the treatment of major depression. Lancet 378: 621-631.

Hrushesky, W., Grutsch, J., Wood, P., Yang, X., Oh, E., Ansell, C. et al. (2009) Circadian clock manipulation for cancer prevention and control and the relief of cancer symptoms. Integr Cancer Ther 8: 387-397.

Jackson, G. (2010) Come fly with me: jet lag and melatonin. Int $\mathcal{f}$ Clin Pract 64: 135.
Jimenez-Caliani, A., Jimenez-Jorge, S., Molinero, P., Fernandez-Santos, J., Martin-Lacave, I., Rubio, A. et al. (2006) Sex-dependent effect of melatonin on systemic erythematosus lupus developed in Mrl/ Mpj-Faslpr mice: it ameliorates the disease course in females, whereas it exacerbates it in males. Endocrinology 147: 1717-1724.

Jung, B. and Ahmad, N. (2006) Melatonin in cancer management: progress and promise. Cancer Res 66: 9789-9793.

Khan, S., Heussler, H., McGuire, T., Dakin, C., Pache, D., Cooper, D. et al. (2011) Melatonin for non-respiratory sleep disorders in visually impaired children. Cochrane Database Syst Rev (11): CD008473.

Knower, K., To, S., Takagi, K., Miki, Y., Sasano, H., Simpson, E. et al. (2012) Melatonin suppresses aromatase expression and activity in breast cancer associated fibroblasts. Breast Cancer Res Treat 132: $765-771$.

Korkmaz, A. (2008) Melatonin as an adjuvant therapy in patients with rheumatoid arthritis. $\mathrm{Br} \mathcal{F}$ Clin Pharmacol 66: 316-317.

Korkmaz, A. and Reiter, R. (2008) Epigenetic regulation: a new research area for melatonin? $\mathcal{F}$ Pineal Res 44: 41-44.

Kostoglou-Athanassiou, I., Athanassiou, P., Treacher, D., Wheeler, M. and Forsling, M. (1998a) Neurohypophysial hormone and melatonin secretion over the natural and suppressed menstrual cycle in premenopausal women. Clin Endocrinol 49: 209-216.

Kostoglou-Athanassiou, I., Treacher, D., Wheeler, M. and Forsling, M. (1998b) Melatonin administration and pituitary hormone secretion. Clin Endocrinol 48: 31-37.

Kostoglou-Athanassiou, I., Treacher, D., Wheeler, M. and Forsling, M. (1998c) Bright light exposure and pituitary hormone secretion. Clin Endocrinol 48: 73-79.

Kumar, C. and Das, U. (2000) Effect of melatonin on two stage skin carcinogenesis in Swiss mice. Med Sci Monit 6: 471-475.

Lewy, A., Ahmed, S. and Sack, R. (1996) Phase shifting the human circadian clock using melatonin. Behav Brain Res 73: 131-134.

Liburdy, R., Sloma, T., Sokolic, R. and Yaswen, P. (1993) ELF magnetic fields, breast cancer, and melatonin: $60 \mathrm{~Hz}$ fields block melatonin's oncostatic action on ER+ breast cancer cell proliferation. f Pineal Res 14: 89-97.

Ling, Z., Tian, Q., Wang, L., Fu, Z., Wang, X., Wang, Q. et al. (2009) Constant illumination induces 
Alzheimer-like damages with endoplasmic reticulum involvement and the protection of melatonin. f Alzheimers Dis 16: 287-300.

Lissoni, P. (1999) The pineal gland as a central regulator of cytokine network. Neuro Endocrinol Lett 20: 343-349.

Lissoni, P. (2002) Is there a role for melatonin in supportive care? Support Care Cancer 10: 110-116.

Lissoni, P., Barni, S., Ardizzoia, A., Olivini, G., Brivio, F., Tisi, E. et al. (1993) Cancer immunotherapy with low-dose interleukin-2 subcutaneous administration: potential efficacy in most solid tumor histotypes by a concomitant treatment with the pineal hormone melatonin. $\mathcal{F}$ Biol Regul Hom Agents 7: 121-125.

Lissoni, P., Barni, S., Brivio, F., Rossini, F., Fumagalli, L., Ardizzoia, A. et al. (1995a) A biological study on the efficacy of low-dose subcutaneous interleukin-2 plus melatonin in the treatment of cancer-related thrombocytopenia. Oncology 52: 360-362.

Lissoni, P., Barni, S., Meregalli, S., Fossati, V., Cazzaniga, M., Esposti, D. et al. (1995b) Modulation of cancer endocrine therapy by melatonin: a phase II study of tamoxifen plus melatonin in metastatic breast cancer patients progressing under tamoxifen alone. B F Cancer 71: 854-856.

Lissoni, P., Bucovec, R., Bonfanti, A., Giani, L., Mandelli, A., Roselli, M. et al. (2001) Thrombopoietic properties of 5-methoxytryptamine plus melatonin versus melatonin alone in the treatment of cancer-related thrombocytopenia. $\mathcal{F}$ Pineal Res 30: 123-126.

Lissoni, P., Rovelli, F., Brivio, F., Fumagalli, L. and Brera, G. (2008) A study of immunoendocrine strategies with pineal indoles and interleukin-2 to prevent radiotherapy-induced lymphocytopenia in cancer patients. In Vivo 22: 397-400.

Maestroni, G. (1999a) MLT and the immunehematopoietic system. Adv Exp Med Biol 460: 395-405.

Maestroni, G. (1999b) Therapeutic potential of melatonin in immunodeficiency states, viral diseases, and cancer. Adv Exp Med Biol 467: 217-226.

Malow, B., Adkins, K., McGrew, S., Wang, L., Goldman, S., Fawkes, D. et al. (2012) Melatonin for sleep in children with autism: a controlled trial examining dose, tolerability, and outcomes. F Autism Dev Disord 42: 1729-1737.

Mao, L., Yuan, L., Slakey, L., Jones, F., Burow, M. and Hill, S. (2010) Inhibition of breast cancer cell invasion by melatonin is mediated through regulation of the p38 mitogen-activated protein kinase signaling pathway. Breast Cancer Res 12: R107.
Masana, M. and Dubocovich, M. (2001) Melatonin receptor signaling: finding the path through the dark. Sci STKE 2001: pe39.

Mazzucchelli, C., Pannacci, M., Nonno, R., Lucini, V., Fraschini, F. and Stankov, B. (1996) The melatonin receptor in the human brain: cloning experiments and distribution studies. Brain Res Mol Brain Res 39: 117-126.

McCarty, M. (2012) Minimizing the cancerpromotional activity of cox-2 as a central strategy in cancer prevention. Med Hypotheses 78: 45-57.

McCune, L., Kubota, C., Stendell-Hollis, N. and Thomson, C. (2011) Cherries and health: a review. Crit Rev Food Sci Nutr 51: 1-12.

Mcikova-Kalicka, K., Bojkova, B., Adamekova, E., Mníchová-Chamilová, M., Kubatka, P., Ahlersová, E. et al. (2001) Preventive effect of indomethacin and melatonin on 7,12-dimethybenz/a/anthraceneinduced mammary carcinogenesis in female SpragueDawley rats. A preliminary report. Folia Biol (Praha) 47: 75-79.

Mediavilla, M., Sanchez-Barcelo, E., Tan, D., Manchester, L. and Reiter, R. (2010) Basic mechanisms involved in the anti-cancer effects of melatonin. Curr Med Chem 17: 4462-4481.

Michalik, A. and Bobiński, R. (2009) 'Jet-lag' pathophysiology and methods of prevention and treatment. Przegl Epidemiol 63: 589-595.

Morgenthaler, T., Lee-Chiong, T., Alessi, C., Friedman, L, Aurora, R., Boehlecke, B. et al. (2007) Practice parameters for the clinical evaluation and treatment of circadian rhythm sleep disorders. An American Academy of Sleep Medicine report. Sleep 30: 1445-1459.

Morin, A., Jarvis, C. and Lynch, A. (2007) Therapeutic options for sleep-maintenance and sleeponset insomnia. Pharmacotherapy 27: 89-110.

Nemeth, C., Humpeler, S., Kallay, E., Mesteri, I., Svoboda, M., Rögelsperger, O. et al. (2011) Decreased expression of the melatonin receptor 1 in human colorectal adenocarcinomas. F Biol Regul Homeost Agents 25: 531-542.

Niles, L., Wang, J., Shen, L., Lobb, D. and Younglai, E. (1999) Melatonin receptor mRNA expression in human granulosa cells. Mol Cell Endocrinol 156: 107-110.

Ochoa-Sanchez, R., Comai, S., Lacoste, B., Bambico, F., Dominguez-Lopez, S., Spadoni, G. et al. (2011) Promotion of non-rapid eye movement sleep and activation of reticular thalamic neurons by a novel MT2 melatonin receptor ligand. $\mathcal{F}$ Neurosci 31: 18439-18452. 
Olcese, J., Cao, C., Mori, T., Mamcarz, M., Maxwell, A., Runfeldt, M. et al. (2009) Protection against cognitive deficits and markers of neurodegeneration by long-term oral administration of melatonin in a transgenic model of Alzheimer disease. f Pineal Res 47: 82-96.

Pandi-Perumal, S., Bahammam, A., Brown, G., Spence, D., Bharti, V., Kaur, C. et al. (2012) Melatonin antioxidative defense: therapeutical implications for aging and neurodegenerative processes. Neurotox Res 28 June [Epub ahead of print].

Pandi-Perumal, S., Smits, M., Spence, W., Srinivasan, V., Cardinali, D., Lowe, A. et al. (2007) Dim light melatonin onset (DLMO): a tool for the analysis of circadian phase in human sleep and chronobiological disorders. Prog Neuropsychopharmacol Biol Psychiatry 31: 1-11.

Pandi-Perumal, S., Trakht, I., Spence, D., Srinivasan, V., Dagan, Y. and Cardinali, D. (2008) The roles of melatonin and light in the pathophysiology and treatment of circadian rhythm sleep disorders. Nat Clin Pract Neurol 4: 436-447.

Paul, M., Miller, J., Gray, G., Love, R., Lieberman, H. and Arendt, J. (2010) Melatonin treatment for eastward and westward travel preparation. Psychopharmacology (Berl) 208: 377-386.

Peschke, E., Stumpf, I., Bazwinsky, I., Litvak, L., Dralle, H. and Mühlbauer, E. (2007) Melatonin and type 2 diabetes - a possible link? F Pineal Res 42 : 350-358.

Petrovsky, N., McNair, P. and Harrison, L. (1998) Diurnal rhythms of pro-inflammatory cytokines: regulation by plasma cortisol and therapeutic implications. Cytokine 10: 307-312.

Pevet, P. and Challet, E. (2011) Melatonin: both master clock output and internal time-giver in the circadian clocks network. F Physiol Paris 105: 170-182.

Pozo, D., García-Mauriño, S., Guerrero, J. and Calvo, J. (2004) mRNA expression of nuclear receptor RZR/RORalpha, melatonin membrane receptor MT, and hydroxindole-O-methyltransferase in different populations of human immune cells. F Pineal Res 37: 48-54.

Ravindra, T., Lakshmi, N. and Ahuja, Y. (2006) Melatonin in pathogenesis and therapy of cancer. Indian F Med Sci 60: 523-535.

Reiter, R. (1995) Functional pleiotropy of the neurohormone melatonin: antioxidant protection and neuroendocrine regulation. Front Neuroendocrinol 16: 383-415.

Reiter, R., Coto-Montes, A., Boga, J., FuentesBroto, L., Rosales-Corral, S. and Tan, D. (2011a) Melatonin: new applications in clinical and veterinary medicine, plant physiology and industry. Neuro Endocrinol Lett 32: 575-587.

Reiter, R., Tan, D. and Fuentes-Broto, L. (2010) Melatonin: a multitasking molecule. Prog Brain Res 181: $127-151$.

Reiter, R., Tan, D., Korkmaz, A. and Manchester, L. (2011b) The disaster in Japan: utility of melatonin in providing protection against ionizing radiation. $\mathcal{F}$ Pineal Res 50: 357-358.

Rios, E., Venâncio, E., Rocha, N., Woods, D., Vasconcelos, S., Macedo, D. et al. (2010) Melatonin: pharmacological aspects and clinical trends. Int $\mathcal{F}$ Neurosci 120: 583-590.

Rivera-Bermúdez, M., Masana, M., Brown, G., Earnest, D. and Dubocovich, M. (2004) Immortalized cells from the rat suprachiasmatic nucleus express functional melatonin receptors. Brain Res 1002: 21-27.

Rögelsperger, O., Wlcek, K., Ekmekcioglu, C., Humpeler, S., Svoboda, M., Königsberg, R. et al. (2011) Melatonin receptors, melatonin metabolizing enzymes and cyclin D1 in human breast cancer. F Recept Signal Transduct Res 31: 180-187.

Rothman, S. and Mattson, M. (2012) Sleep disturbances in Alzheimer's and Parkinson's diseases. Neuromolecular Med 14: 194-204.

Sack, R. (2010) Clinical practice. Jet lag. N Engl f Med 362: 440-447.

Sánchez-Barceló, E., Mediavilla, M. and Reiter, R. (2011) Clinical uses of melatonin in pediatrics. Int $\mathcal{F}$ Pediatr 2011: 892624.

Sánchez-Barceló, E., Mediavilla, M., Tan, D. and Reiter, R. (2010) Clinical uses of melatonin: evaluation of human trials. Curr Med Chem 17: 2070-2095.

Santoro, R., Marani, M., Blandino, G., Muti, P. and Strano, S. (2012) Melatonin triggers p53(Ser) phosphorylation and prevents DNA damage accumulation. Oncogene 31: 2931-2942.

Savaskan, E., Olivieri, G., Brydon, L., Jockers, R., Kräuchi, K., Wirz-Justice, A. et al. (2001)

Cerebrovascular melatonin MT1-receptor alterations in patients with Alzheimer's disease. Neurosci Lett 308: 9-12.

Scher, J., Wankiewicz, E., Brown, G. and Fujieda, H. (2002) MT(1) melatonin receptor in the human retina: expression and localization. Invest Ophthalmol Vis Sci 43: 889-897.

Schernhammer, E., Razavi, P., Li, T., Qureshi, A. and Han, J. (2011) Rotating night shifts and risk of skin cancer in the nurses' health study. $\mathcal{F}$ Natl Cancer Inst 103: 602-606. 
Seely, D., Wu, P., Fritz, H., Kennedy, D., Tsui, T., Seely, A. et al. (2011) Melatonin as adjuvant cancer care with and without chemotherapy: a systematic review and meta-analysis of randomized trials. Integr Cancer Ther 11: 293-303.

Shirazi, A., Ghobadi, G. and Ghazi-Khansari, M. (2007) A radiobiological review on melatonin: a novel radioprotector. F Radiat Res 48: 263-272.

Skene, D. and Arendt, J. (2006) Human circadian rhythms: physiological and therapeutic relevance of light and melatonin. Ann Clin Biochem 43: 344-353.

Skene, D., Lockley, S. and Arendt, J. (1999) Use of melatonin in the treatment of phase shift and sleep disorders. Adv Exp Med Biol 467: 79-84.

Srinivasan, V., Cardinali, D., Srinivasan, U., Kaur, C., Brown, G., Spence, D. et al. (2011a) Therapeutic potential of melatonin and its analogs in Parkinson's disease: focus on sleep and neuroprotection. Ther Adv Neurol Disord 4: 297-317.

Srinivasan, V., Pandi-Perumal, S., Brzezinski, A., Bhatnagar, K. and Cardinali, D. (2011b) Melatonin, immune function and cancer. Recent Pat Endocr Metab Immune Drug Discov 5: 109-123.

Srinivasan, V., Spence, D., Pandi-Perumal, S., Trakht, I. and Cardinali, D. (2008) Jet lag: therapeutic use of melatonin and possible application of melatonin analogs. Travel Med Infect Dis 6: 17-28.

Sulli, A., Maestroni, G., Villaggio, B., Hertens, E., Craviotto, C., Pizzorni, C. et al. (2002) Melatonin serum levels in rheumatoid arthritis. Ann N Y Acad Sci 966: 276-283.

Tan, D., Manchester, L., Terron, M., Flores, L. and Reiter, R. (2007) One molecule, many derivatives: a never-ending interaction of melatonin with reactive oxygen and nitrogen species? F Pineal Res 42: 28-42.
Thorpy, M. (2011) Understanding and diagnosing shift work disorder. Postgrad Med 123: 96-105.

Vijayalaxmi, Thomas, C. Jr, Reiter, R. and Herman, T. (2002) Melatonin: from basic research to cancer treatment clinics. F Clin Oncol 20: 2575-2601.

von Gall, C., Garabette, M., Kell, C., Frenzel, S., Dehghani, F., Schumm-Draeger, P. et al. (2002) Rhythmic gene expression in pituitary depends on heterologous sensitization by the neurohormone melatonin. Nat Neurosci 5: 234-238.

Warman, G., Pawley, M., Bolton, C., Cheeseman, J., Fernando, Fernando, A. 3rd, Arendt, J. et al. (2011) Circadian-related sleep disorders and sleep medication use in the New Zealand blind population: an observational prevalence survey. PLoS One 6: e22073.

Zawilska, J., Skene, D. and Arendt, J. (2009) Physiology and pharmacology of melatonin in relation to biological rhythms. Pharmacol Rep 61: 383-410.

Zee, P. and Goldstein, C. (2010) Treatment of shift work disorder and jet lag. Curr Treat Options Neurol 12: 396-411.

Zee, P. and Manthena, P. (2007) The brain's master circadian clock: implications and opportunities for therapy of sleep disorders. Sleep Med Rev 11: 59-70.

Zee, P., Wang-Weigand, S., Wright, K. Jr, Peng, X. and Roth, T. (2010) Effects of ramelteon on insomnia symptoms induced by rapid, eastward travel. Sleep Med 11: 525-533.

Zha, L., Fan, L., Sun, G., Wang, H., Ma, T. and Zhong, F. et al. (2012) Melatonin sensitizes human hepatoma cells to endoplasmic reticulum stress-induced apoptosis. F Pineal Res 52: 322-331.

Zisapel, N. (2001) Circadian rhythm sleep disorders: pathophysiology and potential approaches to management. CNS Drugs 15: 311-328. 